\title{
Hepatic microsomal mono-oxygenase activity in flounder Platichthys flesus from polluted sites in Langesundfjord and from mesocosms experimentally dosed with diesel oil and copper
}

\author{
R. F. Addison ${ }^{1}$, A. J. Edwards ${ }^{2}$ \\ ${ }^{1}$ Department of Fisheries and Oceans, Bedford Institute of Oceanography, Dartmouth, Canada B2Y 4A2 \\ ${ }^{2}$ Department of Pharmacology, Dalhousie University, Halifax, Canada B3H 4H7
}

\begin{abstract}
Hepatic ethoxyresorufin O-de-ethylase (EROD) and benzo(a)pyrene hydroxylase (B(a)PH) activity in flounder Platichthys flesus increased along a pollution gradient in Langesundfjord, examined during the GEEP Workshop. EROD activity in fish from a reference site was around $100 \mathrm{pmol} \mathrm{min}{ }^{-1} \mathrm{mg}$ microsomal protein ${ }^{-1}$, increasing 5 -fold at 2 moderately polluted sites and a further 2 -fold at a more highly polluted site. $\mathrm{B}(\mathrm{a}) \mathrm{PH}$ activity was around $30 \mathrm{pmol} \mathrm{min}^{-1} \mathrm{mg}$ protein ${ }^{-1}$ in fish from the reference site, and was more than doubled at the polluted sites. Liver residue concentrations of several industrially-derived chlorinated hydrocarbons also increased along the pollution gradient. The data support the conclusion that fish hepatic mono-oxygenase activity may indicate exposure to organic pollutants in the field. Exposure of flounder to diesel oil and copper in mesocosms over several months did not induce EROD or B(a)PH. Enzyme activities were all below those at the field reference site (EROD and B(a)PH around 70 and $20 \mathrm{pmol} \mathrm{min}^{-1} \mathrm{mg}$ protein ${ }^{-1}$ respectively). Total PAH concentrations in liver (fluorescence measurements) did not vary with treatment, suggesting that the experimentally exposed fish did not accumulate inducing compounds.
\end{abstract}

\section{INTRODUCTION}

There exists in various animal tissues an enzymatic detoxification system which: (1) is mainly associated with the smooth endoplasmic reticulum of vertebrate liver, (2) catalyses the conversion of both endogenous and exogenous lipophilic substrates to more water soluble (and therefore more easily excretable) products, (3) requires molecular $\mathrm{O}_{2}$ and $\mathrm{NADPH}$ and involves a CO-binding cytochrome, 'P-450', so-called from the absorption spectrum of its CO complex, and (4) is present at low activity in normal animals, where its function seems to be to degrade endogenous lipophilic substrates such as steroids, but if the animal is exposed to certain organic pollutants (among other chemicals) its activity is induced dramatically, apparently to enhance the degradation of the pollutants.

Hepatic microsomal mono-oxygenase systems in teleost fish share these features, the most important difference being that teleost systems are inducible by fewer chemicals than are mammalian systems (Addi- son 1984), specifically by co-planar polychlorinated biphenyl (PCB) congeners, or polynuclear aromatic hydrocarbons (PAH). In mammals, these chemicals induce a modified hepatic mono-oxygenase system based on cytochromes previously known collectively as $\mathrm{P}-448$. Since induction is dramatic, leading to increases in some activities of 10 - or even 100 -fold, it has been proposed as a sensitive sub-lethal bioassay for such compounds. Here we report its application to flounder Platichthys flesus from a pollution gradient in Langesundfjord, Norway, and in a mesocosm dosing experiment.

\section{MATERIAL AND METHODS}

Platichthys flesus were sampled and transported as described in Bakke et al. (1988) and Follum \& Moe (1988). On arrival at the University of Oslo, Norway, they were immediately sampled, weights, sex and any obvious features being recorded. Livers were dissected 
out carefully, to avoid rupturing the gall bladder, weighed and homogenised $(1: 4$ to $1: 10 \mathrm{w} / \mathrm{v})$ in $1.15 \%$ $(\mathrm{w} / \mathrm{v})$ aqueous $\mathrm{KCl}$, using six vertical strokes of a teflonglass homogeniser cooled in ice. The crude homogenate was centrifuged at $10000 \times g$ for $20 \mathrm{~min}$ at $4{ }^{\circ} \mathrm{C}$ to remove mitochondria and cell debris; the supernatant was centrifuged at $100000 \times g$ for 1 h at $4{ }^{\circ} \mathrm{C}$ to prepare a microsomal pellet (and the supematant discarded). The pellet was resuspended in $1.15 \% \mathrm{KCl}$ and used for all further analyses.

Microsomal 7-ethoxyresorufin O-de-ethylase (EROD) was determined essentially by the method of Burke \& Mayer (1974), using a Turner model 430 spectrofluorimeter modified to allow temperature control at $20^{\circ} \mathrm{C}$. Activity was calculated from a calibration curve prepared with resorufin (Pierce) in the 10 to $50 \mathrm{nM}$ range. Benzo(a)pyrene hydroxylase (B(a)PH) was determined essentially as described by Nebert \& Gelboin (1968) at $25^{\circ} \mathrm{C}$ using quinine dihydrochloride as a secondary standard for routine determinations; this was standardised against authentic 3-hydroxybenzo(a)pyrene (Midwest Research Institute, Kansas City, MO, USA). Proteins were determined by the method of Lowry et al. (1951) using bovine serum albumin as standard.

Samples of liver tissue were frozen for later chemical analysis. Chlorinated hydrocarbon determinations were as described by Addison et al. (1986). Chlorobiphenyl congener mixtures (National Research Council of Canada) and DDT-group insecticides, hexachlorobenzene and octachlorostyrene, were identified by comparison of retention times on open-tubular ECD $\mathrm{GC}$ after dehydrochlorination and clean-up. PAH were extracted from saponified liver samples, cleaned up on Florisil and determined fluorimetrically in terms of B(a)P equivalents, as described by Dunn (1976).

\section{RESULTS AND DISCUSSION}

Table 1 shows relevant biological data from Platichthys flesus obtained from field sites in Langesundfjord. Flounder from the reference site (1) were transported in aerated rather than oxygenated containers, and arrived at the laboratory in poorer condition than those obtained later. With the exception of samples from Site 2, all fish were mature adults (predominantly females) weighing around $400 \mathrm{~g}$; only 5 mature adults could be obtained from Site 2, the rest being small or immature. Analysis of all samples showed that microsomal protein content, liver somatic index and $\mathrm{B}(\mathrm{a}) \mathrm{PH}$ activity differed significantly between fish weighing more or less than $200 \mathrm{~g}$. Since, in other species, MFO activity varies with body weight (Addison \& Willis 1982, Edwards et al. 1987), data from these smaller fish were discarded, and statistical analyses done only on fish weighing over $200 \mathrm{~g}$.

With the exception of the sample from Site 3, which was just significantly higher than for the reference site, all fish from which data were analysed were of similar weights. Differences in liver somatic index $(100 \times$ liver wt/body wt) and liver microsomal content between sites were few, and not obviously related to the expected degree of contamination. The 2 enzymatic indices of MFO induction both differed dramatically between Site 1 and the other sites, EROD by between 5- and 1D-fold, and B(a)PH by 2- to 3-fold. EROD appeared to be the more sensitive indicator, increasing 5 -fold between Site 1 and Sites 2 and 3, and doubling again for Site 4. EROD and B(a)PH in all samples were themselves significantly correlated $(r=0.52, n=40$, $p<0.01$ ).

The trend shown in EROD and $\mathrm{B}(\mathrm{a}) \mathrm{PH}$ activity across the field sites is similar to that observed for hepatic

Table 1. Platichthys flesus. Biological variables and indices of hepatic MFO activity in fish from 4 Langesundfjord sites and 4 mesocosm basins in a dosing experiment: mean $\pm \mathrm{SD}$ of liver microsomal protein $\left(\mathrm{mg}^{-1}\right.$ ), ethoxyresorufin $\mathrm{O}$-de-ethylase (EROD) and benzo(a)pyrene hydroxylase (B[a]PH, both in pmol $\mathrm{min}^{-1} \mathrm{mg}$ protein ${ }^{-1}$ )

\begin{tabular}{|c|c|c|c|c|c|c|}
\hline & $\begin{array}{c}n \\
M / F\end{array}$ & $\begin{array}{l}\text { Fish wt } \\
(\mathrm{g})\end{array}$ & $\begin{array}{l}\text { Liver wt } \\
\text { (\% fish wt) }\end{array}$ & $\begin{array}{l}\text { Microsomal } \\
\text { protein }\end{array}$ & EROD & $\mathrm{B}(\mathrm{a}) \mathrm{PH}$ \\
\hline \multicolumn{7}{|c|}{ Site } \\
\hline 1 & $3 / 8$ & $431 \pm 148$ & $2.39 \pm 1.19$ & $16.6 \pm 6.4$ & $91 \pm 41$ & $33.5 \pm 21.2$ \\
\hline 2 & $1 / 4$ & $482 \pm 182$ & $2.00 \pm 0.45$ & $22.4 \pm 3.6^{\circ}$ & $489 \pm 327^{\circ}$ & $72.3 \pm 51.3^{\circ}$ \\
\hline 3 & $4 / 8$ & $529 \pm 59^{\circ}$ & $2.75 \pm 0.37$ & $17.3 \pm 3.4$ & $569 \pm 168^{\circ}$ & $93.3 \pm 57.5^{\circ}$ \\
\hline 4 & $2 / 10$ & $502 \pm 176$ & $2.58 \pm 0.69$ & $18.0 \pm 5.8$ & $1206 \pm 462^{\circ}$ & $90.2 \pm 52.2^{\circ}$ \\
\hline \multicolumn{7}{|c|}{ Basin } \\
\hline $\mathrm{C}$ & $5 / 6$ & $272 \pm 97$ & $2.45 \pm 1.23$ & $20.6 \pm 7.8$ & $53 \pm 39$ & $7.8 \pm 6.7$ \\
\hline L & $1 / 3$ & $319 \pm 75$ & $3.62 \pm 0.89$ & $19.4 \pm 3.3$ & $84 \pm 28$ & $25.7 \pm 6.8^{\circ}$ \\
\hline M & $2 / 7$ & $361 \pm 78^{\circ}$ & $2.95 \pm 1.59$ & $24.6 \pm 6.7$ & $65 \pm 27$ & $15.7 \pm 7.0$ \\
\hline $\mathrm{H}$ & $4 / 1$ & $251 \pm 40$ & $3.34=1.15$ & $21.6 \pm 2.7$ & $84 \pm 83$ & $30.5 \pm 27.0$ \\
\hline
\end{tabular}


Table 2. Platichthys flesus. Liver concentrations of total chlorobiphenyls (PCB), hexachlorobenzene (HCB) and octachlorostyrene (OCS, all in $\mu \mathrm{g} \mathrm{g}^{-1}$ wet wt) for 3 of the 4 Langesundfjord sites (mean $\pm \mathrm{SD}$ )

\begin{tabular}{|c|c|c|c|c|}
\hline & $n$ & Total PCB & $\mathrm{HCB}$ & OCS \\
\hline \multicolumn{5}{|c|}{ Site } \\
\hline 1 & 5 & $0.51 \pm 0.15$ & $0.23 \pm 0.16$ & $0.06 \pm 0.02$ \\
\hline 2 & - & - & - & - \\
\hline 3 & 10 & $3.05 \pm 1.58^{\circ}$ & $1.80 \pm 1.16^{\circ}$ & $0.94 \pm 1.30$ \\
\hline 4 & 11 & $3.55 \pm 3.32^{\circ}$ & $1.37 \pm 0.88^{\circ}$ & $0.71 \pm 1.07$ \\
\hline \multicolumn{5}{|c|}{ Significance as for Table 1} \\
\hline
\end{tabular}

concentrations of residues of chlorinated hydrocarbons usually associated with industrial processes. Thus, chlorinated biphenyls ranging from IUPAC 31 (a trichlorobiphenyl) to IUPAC 209 (decachlorobiphenyl) increased in concentration from Site 1 to Sites 3 and 4 (Table 2 and Appendix 1, Table 11). (No samples were available from Site 2.) IUPAC 138, 153, 207 and 209 predominated.

Hexachlorobenzene ( $\mathrm{HCB}$ ) and octachlorostyrene (OCS), both of which may be by-products of chloralkali processes (Mumma \& Lawless 1975, Kuehl et al. 1976) increased similarly, though the differences were significant only in the case of HCB. EROD activity was significantly positively correlated with total PCBs ( $r=$ $0.52, n=26, p<0.01$ ) though not with any of the individual PCB congeners, nor with $\mathrm{HCB}$ or OCS; $\mathrm{B}(\mathrm{a}) \mathrm{PH}$ activity was not positively correlated with any of these variables. Since neither HCB nor OCS appears to be an MFO inducer in fish (Law \& Addison 1981) the absence of correlations between these residues and MFO activity is not surprising. Nothing further can be said about the correlation with total PCBs since so little is known about the biochemical toxicology of PCB congeners towards fish.

The trend in hepatic EROD and $\mathrm{B}(\mathrm{a}) \mathrm{PH}$ is also very similar to that observed for total PCB and PAH levels in tissues of mussels and crabs (Appendix 1). Thus, across Sites 1 to 4, mussel PCB (total, as Aroclor 1254) increased from about 80 to $270 \mathrm{ng} \mathrm{g}^{-1}$ dry wt and total PAH from about 2 to $15 \mu \mathrm{g} \mathrm{g}^{-1}$ dry wt. In crabs, PCB ranged from 160 to $460 \mathrm{ng} \mathrm{g}^{-1}$ and PAH from 160 to $250 \mathrm{ng} \mathrm{g}^{-1}$. Although the differences are not dramatic, particularly for crab PAH, they are internally consistent and confirm the presence of the expected pollutant gradient.

Results from the mesocosm experiment were less satisfactory. Table 1 summarises the data on MFO activity in flounder weighing over $200 \mathrm{~g}$. Few differences were seen, though to some extent this reflected the small sample sizes of fish over $200 \mathrm{~g}$, and the high variances. (However, even if all samples were included, there was still no consistent variation in $\mathrm{MFO}$ indices with treatment). EROD activity was slightly, but not significantly, higher in all treated groups (L: low, $\mathrm{M}$ : medium, $\mathrm{H}$ : high doses of diesel oil and copper mixture) than in controls (C), and $\mathrm{B}(\mathrm{a}) \mathrm{PH}$ activity was significantly induced in the $\mathrm{L}$ and $\mathrm{H}$ groups. However, analysis of total PAH in flounder Platichthys flesus liver showed no difference in residues accumulated by fish in different treatments; all groups had mean concentrations (in B(a)P equivalents) of around $0.7 \mu \mathrm{g} \mathrm{g}^{-1}$ wet wt. Although this is only a rough indication of total PAH residues, the concentrations are reasonable (cf. Neff 1979) and are similar to those found in the invertebrates from the experimental mesocosms. These latter data show that, in the crabs and mussels, total PAH levels followed the expected trend, increasing with dose, but PAH in sediments were constant at around $1 \mu \mathrm{g} \mathrm{g}^{-1}$ dry wt across treatments (Appendix 1).

Field results showed convincingly that hepatic MFO activity in flounder followed the observed pollution gradient in Langesundfjord, as indicated by flounder hepatic PCB concentrations, and by mussel and crab residue burdens. This is to be expected: there now exists a large body of literature showing that fish exposed to petroleum hydrocarbons (especially PAH) have induced hepatic mono-oxygenase activity (e.g. Addison \& Payne 1987). The present results are slightly unusual in that $\mathrm{B}(\mathrm{a}) \mathrm{PH}$ appeared not to be as sensitive an indicator of induction as did EROD, but this may be explicable in several ways: for example, the particular suite of chemicals to which these fish were exposed may have selectively induced EROD. This point illustrates the need to consider biological effects in the context of relevant chemical analyses.

A possible criticism of the results is that the low activity in reference site fish may reflect their poorer transport conditions. However, this seems unlikely: in our experience, MFO activity responds to varying conditions over a matter of days rather than hours, and only $6 \mathrm{~h}$ were required for catch and transport from Langesundfjord. Also, MFO activity in reference site fish was higher than that in any of the mesocosm samples, which appeared to be in satisfactory condition.

The absence of induction in mesocosm flounder requires some explanation. The fact that EROD and $\mathrm{B}$ (a)PH activity for all doses was below that of flounder from the field reference site suggests that the latter may have been partially induced. This, combined with the absence of any accumulation of $\mathrm{PAH}$ in the sediments of the mesocosm basins, suggests that the mesocosm flounder simply did not accumulate $\mathrm{PAH}$, and this was borne out by the liver PAH residue analyses. Fish appear to accumulate organic pollutants, including PAH, mainly from food rather than water (e.g. Neff 
1979) and a dietary route may simply not have existed in the mesocosms. This raises the question of why the mussels and crabs from the mesocosm accumulated PAH: in the former case at least, small particulate material to which PAH would be adsorbed would have been filtered by the mussel during normal feeding. It is conceivable that crabs would scavenge small food particles to which PAH would have become adsorbed, and that such a route would be unavailable to the flounder.

\section{LITERATURE CITED}

Addison, R. F. (1984). Hepatic mixed function oxidase (MFO) induction in fish as a possible biological monitoring system. In: Cairns, V. W., Hodson P. V., Nriagu, J. O. (eds.) Contaminant effects on fisheries. Wiley, Toronto, p. 51-60

Addison, R. F., Payne, J. F. (1987). Assessment of hepatic mixed function oxidase induction in winter flounder (Pseudopleuronectes americanus) as a marine petroleum pollution monitoring technique, with an Appendix describing practical field measurements of MFO activity. Can. Tech. Rept. Fish. Aquat. Sci. 1505

Addison, R. F., Willis, D. E. (1982). Variation of hepatic ethoxycoumarin O-de-ethylase activity with body weight and other factors in brook trout (Salvelinus fontinalis). Can. J. Fish. aquat. Sci. 39: 924-926

Addison, R. F., Zinck, M. E., Smith, T G. (1986). PCBs have declined more than DDT-group residues in Arctic ringed seals (Phoca hispida) between 1972 and 1981. Environ. Sci. Technol. 20: 253-255

Bakke, T., Follum, O. A., Moe, K. A., Sørensen, K. (1988). The GEEP Workshop: mesocosm exposures. Mar. Ecol. Prog. Ser. $46: 13-18$
Burke, M. D., Mayer, R. T (1974). Ethoxyresorufin: direct fluorimetric assay of a microsomal O-dealkylation which is preferentially inducible by 3-methylcholanthrene. Drug Metab. Disp. 2: 583-588

Dunn, B. P. (1976). Techniques for determination of benzo(a)pyrene in marine organisms and sediments. Environ. Sci. Technol. 10: 1018-1021

Edwards, A. J., Addison, R. F., Willis, D.E., Renton, K.W (1987). Seasonal variation of mixed function oxidases in the liver of winter flounder (Pseudopleuronectes americanus). Mar, environ. Res. (in press)

Follum, O. A., Moe, K. A. (1988). The GEEP Workshop: field sampling. Mar. Ecol. Prog. Ser. 46: 7-12

Kuehl, D. W., Kopperman, H. L., Veith, G. D., Glass, G. E. (1976). Isolation and identification of polychlorinated styrenes in Great Lakes fish. Bull. environ. Contam. Toxicol. 16: $127-132$

Law, F. C. P., Addison, R. F. (1981). Response of trout hepatic mixed function oxidases to experimental feeding of ten known or possible chlorinated environmental contaminants. Buil. environ. Contam. Toxicol. 27: 605-609

Lowry, O. H., Rosebrough, N. J., Farr, A. L., Randall, R. J (1951). Protein measurement with the Folin phenol reagent. J. biol. Chem. 193: 265-275

Mumma, C. E., Lawless, E. W. (1975). Survey of industrial processing data. Task 1 - hexachlorobenzene and hexachlorobutadiene pollution from chlorocarbon processes. US EPA Report 560/3-75-003 (available as NTIS PB 243-641/8SL)

Nebert, D. W., Gelboin, H. V. (1968). Substrate inducible microsomal aryl hydroxylase in mammalian cell culture. J. biol. Chem. 243: 6242-6249

Neff, J. M. (1979). Polycyclic aromatic hydrocarbons in the aquatic environment: sources, fates and biological effects. Applied Science Publishers Ltd., London. 